\title{
Challenges for sustainable development strategies in oil and gas industries
}

\author{
Ali Asghar Sadeghi MOJARAD \\ The Bucharest University of Economic Studies, Bucharest, Romania \\ sadeghimojarad@hotmail.com \\ Vahid ATASHBARI \\ The University of Alaska Fairbanks, Alaska \\ vatashbari@alaska.edu \\ Adrian TANTAU \\ The Bucharest University of Economic Studies, Bucharest, Romania \\ adrian.tantau@fabiz.ase.ro
}

\begin{abstract}
The oil and gas industries remain an important drive for the world economy. On one hand, global demand for fossil fuels is still rising, and on the other hand, companies face complex investment challenges due to the harsh operational environment of exploration and production activities. Workforce regulations aim to provide a safe and secured working environment. However, exploration and production activities still cause local and global environmental risks such as groundwater contamination, or climate change in broader scale. Analyzing and reporting mechanisms are key performance indicators of sustainable development at the level of oil and gas companies. Obtaining and analyzing required data, nevertheless, seem to be a persistent challenge as to what degree these findings can affect the routine and strategic decisions of the oil and gas companies. In order to enable oil and gas companies to measure and control risks and manage incidents, artificial intelligent technologies in extended monitoring and supervising E\&P operations is known to be an efficient prevention strategy. Such tools not only aid in profitability of the oil and gas companies, but also increase awareness of environment and climate change to act more responsibly. In this study, the significances of environmental policies were investigated through interviews with executives and stakeholders, revealing that the implementation of environmental protection policies is affected by the financial stability of the companies, and under severe economic situations, companies seem less enthusiastic in strictly implementing those policies. This paper provides a comprehensive review of emerging technologies in addressing existing and foreseen challenges in sustainable development in oil and gas industries, with the aim of suggesting prime solutions for strategic planning attempts.
\end{abstract}

Keywords: sustainability, policies, challenges, innovation, smart solutions, oil and gas industry.

\section{Introduction}

The oil and gas industry continues to be the main source of energy in the world, and is one of the most important parameters that have left an impact on the growth of the global economy. Oil and Gas industries supply more than $50 \%$ of global fuel consumption, and hydrocarbons are expected to remain the superior source of energy in 2035 (BP, 2017b). Daily production of oil was around 96.3 million barrels in 2016 which yields 2 liters per day per each person in the world (IEA, 2016a). Continued research of BP shows that till 2035, natural gas will become the second largest fuel source, so fossil fuel demand is rising. Hence, continuous exploration and production activities in the world. The expected needs of investment in the upstream section will be 700 USD billion yearly till 2040 to meet the 
global energy needs as IEA stated. On the other hand, the financial markets of the world now have billions of dollars in turnover from the daily production of more than 96 million barrels of oil (IEA, 2016b), which has left economic impacts on the regional markets of the countries that are either exporters of oil and gas or importers of fossil fuels. Apparently, there has been no precise forecast for changing the principles of energy market neither on demand nor the supply side. But it is obvious that from each barrel of oil however, there are many more barrels of waste generated (Ite, Ibok, Ite, \& Petters, 2013).

\section{Overview of the O\&G industry}

To be able to properly understand the role of oil and gas industry with respect to sustainable development, and to properly assess the challenges and the roles of each component of the oil business chain, there is need for a proper understanding of the structure of this industry (Schweitzer, 2010a). The oil and gas industries are usually divided into three major sectors: Upstream, Midstream and Downstream (Figure 1).

- Upstream sector is known as "E\&P", where "E" stands for exploration and "P" for production that each of them may be divided to other categories depending on the characteristics of the reservoir and circumstances of the field. In upstream, searching of potential on-shore or off-shore crude oil and natural gas is performed, then exploratory and appraisal wells are drilled. Commercial production then starts after drilling a number of development wells and connecting them to the surface production unit and transportation facilities.

- Downstream and Midstream sectors are supplements of the upstream section to deliver the products to consumers. Midstream is mainly comprised of transportation means from the well to the processing facilities, and then to refineries.

- The main component of the downstream sector however is refining of crude oil and processing of natural gas. This process provides gasoline or petrol, kerosene, diesel, fuel or jet oil, lubricant waxes, asphalt, NLG or LPG besides petrochemicals. Delivery to the end user is also a part of downstream sector.

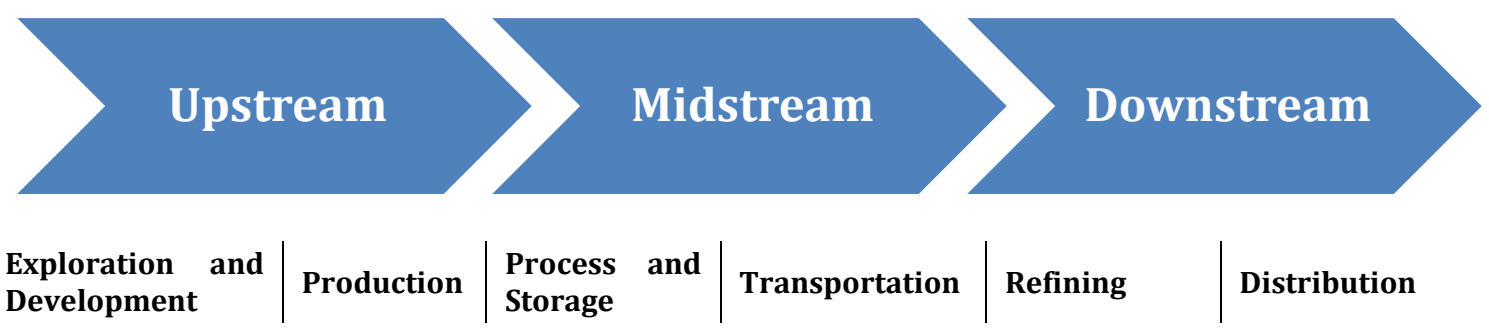

Figure 1. Oil and Gas value Chain

Source: Authors' own research.

The major developers of the petroleum industry can be grouped as national oil companies (NOC) and international oil companies (IOC). These companies often operate in an integrated manner, encompassing both upstream and downstream (Whitson, 2009), forming the basic structure of this industry. There are plenty of smaller size businesses that contribute to the main activities of the oil and gas industry (i.e. E\&P and refining), or supply services to NOC's, IOC's and other type of companies involved in this industry. 


\section{Oil and Gas industry and sustainability}

In recent years, the oil and gas industry has also been called to deliberate over environmental protection. The severity of environmental crises and climatic change emanated from the production of oil and gas has left grave repercussions for many societies. Major oil companies have been accused of creating disorder in global environmental issues and they face reliability issues by policy-makers and the public from around the world. People of the world are re-examining how fossil fuels are used in their lives (WEF, 2016). This negative mentality is based on several evidences, issues like the Santa Barbara oil spill in 1969 in California and Deep water Horizon disaster in the Gulf of Mexico in 2010 .These environmental disasters have prompted the public into seeking both measurable improvement in performance and greater transparency and operation in oil and gas industries, pertaining to sustainability. Consequently, the oil and gas industries, like other industries, have redefined their business development strategy on the basis of sustainable development while some of them have become responsive toward some of the operational criticisms (Weaver, 2003). The oil companies adopting supportive policies for protecting the environment to ensure safety measures in exploration and production activities.

This is how the concept of sustainable development has entered into the oil and gas industry literature, and terms such as Green Economy, Sustainable Development, Social Responsibility and Risk Management have become commonplace in lectures and seminars presented by oil companies (Schweitzer, 2010a). In the same vein, , oil company's top management are now in favor of smart solution implementations and innovations such as Performance Assurance and Operation Risk Management, Contaminated Site Management and Air Quality and Climate Change. However there is always a difference between what oil companies declare about sustainability and how they perform. For this reason, considerable studies have been conducted and the overall conclusion conveys that sustainable development has seriously gained entrance into the decision-making levels of major oil and gas producing companies, although in reality, the oil industry still remains one of the main causes of environmental degradation and climate change (Schweitzer, 2010a). For this reason, organizations such as IPIECA, API and OGP are very active in organizing sustainable development management standards in the oil and gas sector, and encouraging oil and gas companies and their shareholders to provide voluntary reports as one of their priorities, thereby consolidating with, and adhering to sustainable development strategies (Schneider et al., 2013). The study conducted herewith, reveals that in spite of the very simple and effective definitions about sustainability provided in the past decades, there are still many ambiguities around this concept and in practice, this concept has exhibited contradictory interpretations.

\section{Challenges of sustainability in oil and gas industry}

Over the past years, the petroleum industry has faced several complex challenges. The oil industry should invest pro rata to the increasing demand for energy in the world, and on the other hand, in view of the more competitive activities in these sectors, this industry should reduce the total cost of production of hydrocarbon resources, while simultaneously adhering to the environmental laws and social responsibilities. Some significant challenges for oil and gas industry include: 
- Price fluctuation (Regnier, 2007);

- Increasing pressure on managers by shareholders focusing on value creation instead of output because of low returns on investments (Ramos, Taamouti, Veiga, \& Wang, 2017);

- Complexity of drilling and production process (Gupta \& Grossmann, 2017);

- Increasing demand for oil and gas in most regions (BP, 2017a);

- HSE compliance remaining critical - especially in the current environment of volatile prices and cost savings (Neill, 2017);

- Protection of the social license of operation (Tomlinson, 2017) and corporate social responsibilities (Banerjee, 2017);

- Fluctuation of fiscal regimes;

- R\&D and innovation (Hall \& Vredenburg, 2003);

- Handling growing size of data and knowledge management (Bratianu \& Bolisani, 2015); and

- Unstable partnership of NOC-IOC: (Whitson, 2009).

The challenges mentioned above are a set of effective factors that have hit major oil and gas producing companies in the process of implementing sustainable development policies. As mentioned earlier, the production of every barrel of crude oil, refining and transportation of petroleum products to the customer, due to the high pressure- high temperature conditions of underground reservoirs, and the use of a variety of chemicals to safely drill and produce hydrocarbons, is an industry that causes contamination and pollution. In general, the challenges of sustainable development in the oil and gas sector can be categorized as follows.

- Flaring and venting;

- Decommissioning of oil and gas installations;

- Oil storage tank disposal;

- Managing drill cuttings;

- Produced water disposal/treatment;

- Managing drilling muds and fluids;

- Estimating and validating greenhouse gas emissions;

- Subsidence;

- Spills;

- Safety; and

- Enhanced profitability.

Each of the abovementioned challenges has created many environmental concerns and occasionally environmental crises in the past. Of course, some major oil companies have made decisions about each of these challenges, and billions of dollars have been spent annually on improving methods and technologies, and dealing with indigenous communities around oil and gas facilities. Also, over the past years, national oil companies under the pressure of governments, and international oil and gas companies under pressure from public and lawmakers, have taken a number of measures to address the challenges of sustainable development in the petroleum industry. 
And also, lobbying continues to take place among some oil company executives and local governments (Schweitzer, 2010b), and worries about the repetition of bitter memories such as the fire of the Alpha Piper oil rig in 1988 causing the death of 167 people and so on, is still in the minds of environmental activists. Meanwhile, a number of oil and gas companies have also made significant strides in the social corporate responsibility (SCR) sector, and they most effectively support the achievement of the SDGs and the 2030 Agenda (UNDP, 2016). Such companies do not guarantee a world free of any environmental crises, but have demonstrated some significant efforts to avoid such incidents. However, the existed conditions proved that they can do much more than what they claim.

\section{Sustainable drivers}

The world's population is steadily increasing, ensuing the need for more affordable and accessible energy (Pérez-Lombard, Ortiz, \& Pout, 2008). The fluctuation in pricing has led to staggering competition in the energy supply market incurring reduction of prices. Over the past decades, regional, cultural and security disputes have steadily increased reaching their peaks in recent times. Under such critical circumstances, the provision of sustainable energy has greatly increased the risk prospects in corporate activities, leading to higher investment costs. Climate change is steadily exacerbated every year. The world is facing devastating consequences of global climate change. There is danger of raising sea level, and more villages and towns are at risk of floods and storms. This is one aspect of challenges of which addressing requires long term efforts. Meanwhile, with the steady rise in production costs, the expectations of shareholders and owners of enterprises have also increased. The shareholders consider economic gain as the priority of their activities, and expect a steady increase in the profitability through executives of business entities. All of the several factors, such as increasing population, escalating competition, global climate change, and shareholder expectations, regional trade patterns (Miron et al., 2010) are Sustainable Drivers that have instigated the business environment with risks and tension. Identifying challenges and addressing each challenge is an ongoing battle for oil and gas companies and they are constantly improving their business plan to be as comprehensive and consistent as possible. This paper provides insights into some of the existing challenges, and discusses statistical results of a survey over some of the sustainability indicators.

\section{Research methodology}

This study presents and discusses some of the results of a survey that has been primarily conducted by Tantau, Khorshidi, and Sadeghi Mojarad (2017). The survey has targeted 128 correspondents from various oil and gas companies and service contractors within the Middle East region, focusing on the prior two years. That was the period in which the oil price was still declining, and then started to gradually recover in 2016. In this study, some new outcomes are presented, and interpretations are further discussed. This paper utilizes quantitative research to find the association of a dependent variable such as organization type, action plan, training and relation to customer in the practice of $0 \& G$ companies with other independent variables like the concept of sustainability. It is then followed by qualitative analysis as all the secondary data highlight challenges to sustainability, and are derived from various sources such as the annual reports of oil and gas companies, the United Nations and the NGO, and documents on sustainable development. This study also examines the issues affecting expectations from the measurable efforts of oil and gas 
companies in sustainable development and the constraints of oil and gas companies to maximize their participation in sustainability. Such approach is known to collect evidence and find some information that was not been emphasized or has not been given attention to previously. Data analysis and interpretation have been carried out by a team of statistical experts, then discussed and interpreted by the authors who have been working in this industry, and were CEO's and managers in the oil and gas industry for more than 15 years. To conduct the analysis, it is necessary to examine the interdependency of assessed parameters. One of the best available tools is chi-square test, in which the level of significance of the test (sig) is determined, where any value less than 0.05 indicates a meaningful relationship between the answers. Then, detailed cross tables of such parameters are carefully analyzed. The statistical data were collected within the IBM SPSS software, and further analysis is then carried out using Microsoft Excel spreadsheet and graphs. It must be noted that this survey was conducted in the Middle East, and therefore, the results must be considered local. Albeit, findings of this study may not be applicable to other regions of the world.

\section{Results and discussions}

As explained in the methodology section, the statistical data of the questionnaire were analyzed and results are presented and discussed in this section. To validate some of the cross-linked results, interdependency of the studied parameters were examined, which yielded a perfect agreement. The acceptable threshold criteria for the significance of the test, which was set in the previous section was met in all of the data discussed herein.

According to this survey, $47 \%$ of the respondents stated that there isn't any specific department regarding any aspects of sustainability in their organization (Figure 2). This indicates a huge gap between ideal and real position of the industry in terms of getting prepared for the challenges of the future. $100 \%$ of the respondents, who responded "yes" to this question, are from small sized companies with 11-15 employees. Larger sized companies might have any department responsible for sustainability, but the employee who answered the questions may not be aware. That comprises $19 \%$ of the responses that still is a noticeable value.

Do you have any specific department regarding any aspects of sustainability in your organization/company?

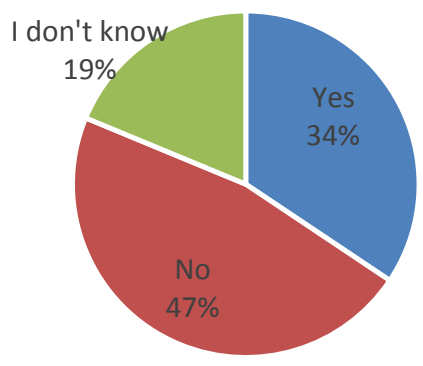

Figure 2. Responses to question about existence of any specific department regarding any aspects of sustainability in respective organization

Source: Authors' own research. 
On the other hand, almost half of the respondents were certain that their respective entities don't have any action plan for Biodiversity and ecosystem services (Figure 3). Among those who believe that their organizations have some sort of biodiversity plan, $54 \%$ are private, and $26 \%$ are state owned. Although biodiversity has been a kind of emerging concept among many companies in the Middle East, the statistics seem less than ideal. Perhaps this is one of the first things that the businesses should emphasize when revising their strategic plans.

\section{Does your company have action plan for Biodiversity and ecosystem services?}

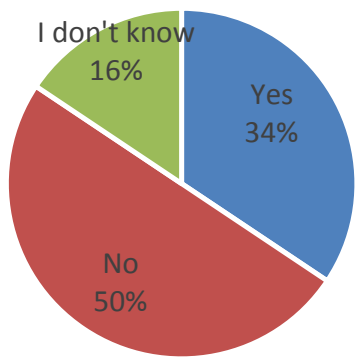

\section{Figure 3. Responses to question about having action plan for Biodiversity and ecosystem services}

Surprisingly, $66 \%$ of the respondents stated that their respective companies have had some sort of job creation or skill development programs during the 2-year period ending to the date that the survey is conducted (Figure 4). Out of this number, none was small size company (with 0-10 employees), 16 (12.5\%) were companies with 11-49 employees, and 68 (53\%) were companies with 100-499 employees (Table A-1). This reveals a remarkable fact that keeping the job market alive is mostly on the shoulders of mid-size to large enterprises. $62 \%$ of these companies are private, and $34 \%$ are state owned (Table A-2). Again, it may seem that the private sector has done better job in maintaining the dynamics of job market than state owned organizations. The reason could be hidden in the fact that state owned companies might have robust hiring and training policies with less flexibility. During industry downturn, they tend to freeze employment, but their training schedule isn't necessarily affected by the oil and gas market. On the other hand, private sector aims to secure a minimum amount of profit margin, so the companies may fire personnel, and either hire people with special expertise, or train their existing employees with advanced tools and techniques to maintain the competitive advantage in the market (due to layoffs, net employment rate could be much less than what is shown as new hiring). This might have been the reason why skill development or job creation seems higher in private sector. 
Have your company had any Job creation or skill development program during last 2 years?

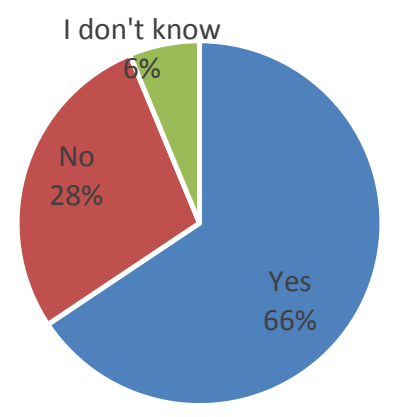

PICBE | 633

Figure 4. Responses to question about having any job creation or skill development program during last 2 years ending to the date of survey

Source: Authors' own research.

During difficult times, a constructive relationship can be a matter of life and death. People/businesses with diverse and improved networks are most likely to survive a crisis than the isolated ones with limited connection. Although companies are different with respect to their customer relation policies, being responsive and supportive supplier would always guarantee long term benefits. Private sector has been known to serve customers/clients better than governmental entities. This has been reflected in Figure 5. $55 \%$ of the companies who got another contract as a result of good customer intimacy are privately owned entities, whereas only 39\% were state owned. Out of total respondents, who responded "yes" to this question, 5.5\% were from 0-10 employee Company, 28\% from 11-49 employee company, 5.5\% from 50-99, and 61\% were from larger size companies (Table A-5). This is because larger companies normally have well established customer relation policies, and therefore, benefit from it all the time, especially during recession.

Does your company / organization awarded any new contract because of good customer intimacy during last 2 years?

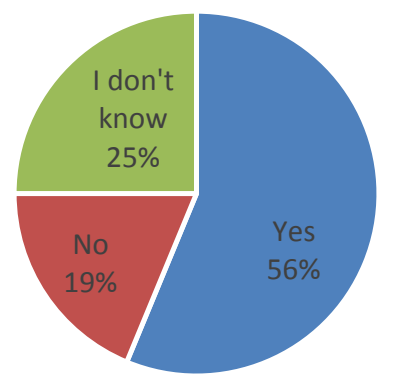

Figure 5. Responses to question about being awarded any new contract because of good customer intimacy during last 2 years ending to the date of survey

Source: Authors' own research.

In another question, the respondents were asked about the most important financial performance in their organization. $79 \%$ of the respondents that stated efficiency as their 
most important performance indicator in the period of 2 years were from private sector, whilst only $14 \%$ were from state owned entities (Figure 6). This is while $45 \%$ of the companies of which the respective respondents considered profitability as the most important indicator of their performance were privately owned, and 54\% were state owned entities (Table A-6). This shows that profitability is more of an interest in governmental companies, whereas efficiency is the top list of performance indicators in private sector. State owned companies normally report to the governments, and as long as a company provides the minimum acceptable profit margin, the government may not be interested in knowing details of how that company performs (efficiency). However, private companies may fall in either one of the following categories. They are either small, which are normally monitored by their board and stakeholders, or large enough to have shares in the stock market, where various shareholders would expect both profit, and increasing trend of share price. If a company doesn't meet the key performance indicators, even if a substantial profit is generated, the stock market would see it as an uncertain asset with no guarantee if such revenue can be repeated in future. That's why, private companies try to present themselves as an active and productive entities that can maintain the profitability through high efficiency. Hence, efficiency is taken more serious in the private sector than governmental organizations.

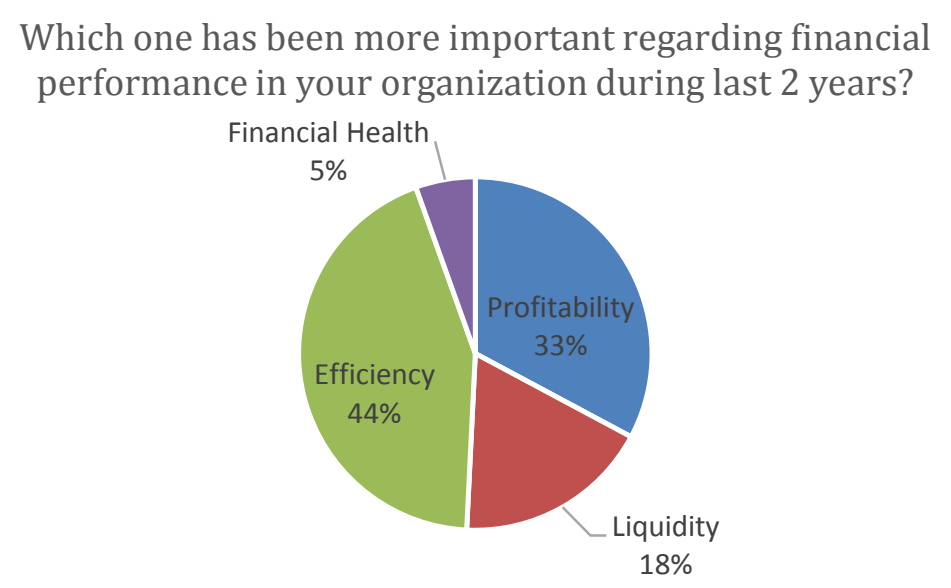

Figure 6. Responses to question about the most important financial performance in the organization during last 2 years ending to the date of survey

Source: Authors' own research.

Surprisingly, none of the respondents from private sector believed that that financial health is an important indicator, whilst it was considered as the most important indicator by $9 \%$ of the respondents from state owned entities (Table A-6). Detailed cross table of the performance indicators with respect to the type of company is provided in the following table. 
Table 1. Cross results of responses to question about the most important financial performance with respect to the type of company.

\begin{tabular}{|l|c|c|}
\hline $\begin{array}{l}\text { Most Important } \\
\text { Performance Indicator }\end{array}$ & Private & $\begin{array}{c}\text { State } \\
\text { owned }\end{array}$ \\
\cline { 1 - 2 } $\begin{array}{l}\text { Most important } \\
\text { performance indicator }\end{array}$ & $25 \%$ & $55 \%$ \\
\hline Profitability & $20 \%$ & $18 \%$ \\
\hline Liquidity & $55 \%$ & $18 \%$ \\
\hline Efficiency & $0 \%$ & $9 \%$ \\
\hline Financial Health &
\end{tabular}

PICBE $\mid 635$

Source: Authors' own research.

Combining the responses to the two last questions yields an interesting fact (Table 2). Among the respondents whose companies got any contract based on good customer intimacy, the greatest performance indicator was profitability (44\%), while efficiency was also considered another important Indicator (39\%, Table A-7). However, the greatest performance indicator of those who were not awarded any contract due to customer intimacy, 83\%, was efficiency. Although efficiency was also a key indicator noted by $39 \%$ of respondents whose companies got contract, it is remarkably less than $83 \%$. Efficiency seems to be more of an internal perspective, and that's why the companies that set it as their priority, were not necessarily successful in obtaining a contract due to customer intimacy. Nevertheless, none of these key performance indicators can necessarily improve relationship with customers, and guarantee the next contract. On the other hand, there is a significant uncertainty about results of this analysis due to a large number of respondents who were not sure about being awarded any contract by customer intimacy ( $25 \%$ who responded I don't know). Among them, financial health was a performance indicator. The results of this discussion are graphically presented in Figure 7.

Table 2. Cross results of responses to question about awarded any new contract because of good customer intimacy with respect to the most important performance indicator

\begin{tabular}{|l|l|l|}
\hline $\begin{array}{l}\text { Being awarded any contract because of } \\
\text { good customer intimacy }\end{array}$ & \multirow{2}{*}{ Yes } & No \\
\hline Most important performance indicator & & \\
\hline Profitability & $44 \%$ & $0 \%$ \\
\hline Liquidity & $17 \%$ & $17 \%$ \\
\hline Efficiency & $39 \%$ & $83 \%$ \\
\hline Financial Health & $0 \%$ & $0 \%$ \\
\hline \multicolumn{2}{|c}{ Source: Authors' own research. }
\end{tabular}


Profitability as the most important performance indicator

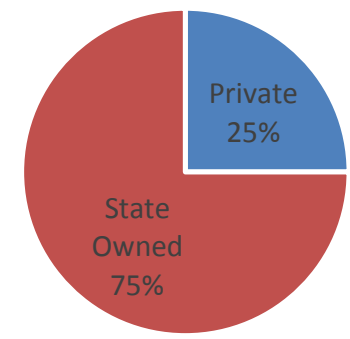

Efficiency as the most important performance indicator

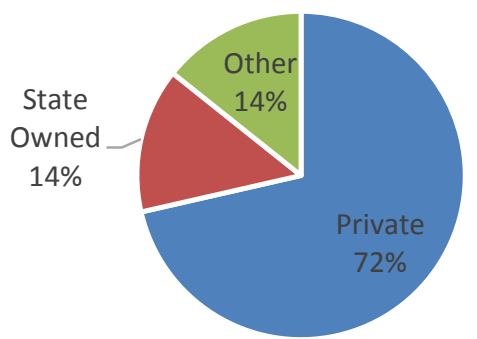

Figure 7. Frequency of the respondents whose respective companies were awarded a contract as a result of good customer intimacy. Left) company type of those who stated profitability as the main performance indicator. Right) company type of those who stated efficiency as the main performance indicator

Source: Authors' own research.

Aforementioned figures and associated discussions unveil a significant fact about the businesses included in this survey: companies in this region severely lack a consistent strategy, and a robust policy for sustainable development. Employees and managers occasionally are not in full compliance with their value statements, which is mostly due to lack of proper communication and education within their respective organizations. There is a remarkable portion of employees who are unaware of responsible department or directorate for sustainability in the company they work for. On top of that, businesses also vary with respect to their attitude toward clean energy supply and where on the KPI list shall include environmental protection. Perhaps, profitability is as essential to the entire value of an entity as efficiency, but "why private and governmental companies have totally different viewpoint in this regard" is a key question that sheds light on some of dark aspects of sustainability in this region. Although all businesses strive for preponderance in the future's competitive and rapidly evolving energy market, their influence significantly vanishes from the lack of long term plans, which stops them from appropriately responding to the newly emerging challenges of this market.

\section{Conclusion}

The use of information technology, intelligent control tools, intelligent maintenance programs as well as organizational reform and targeted investment in the R \& D sector to fulfill the goals of sustainable development, includes a series of measures that will restore public confidence in the oil industry, and in fact, in this research, it became clear that the implementation of sustainable development requires a change in the minds and policies of oil and gas producing companies. According to this study, private sector seemed better able to respond to the price fluctuations due to their structural constitution and values. Skills development and job creation during the industry downturn were a priority within the private sector while the governmental entities tended to freeze the employment, and therefore, their contribution to the job market was minimized. In terms of benefiting from customer intimacy, larger sized companies were doing better off, which reflects efficiency of 
the customer relation policies they might have adopted in their organizations. Profitability and efficiency were the main performance indicators among state owned and private companies respectively. Should a company have to improve the strategic plan in order to boost the sustainability, all of these findings must be utilized. One of the most effective tools is using smart and intelligent tools to continuously monitor the activities and services to customers, especially where the number and type of customers are large, then adopting dynamic and more responsive policies that can maximize values of the entire industry. Maintaining a biodiversity policy is also another emerging requirement within the petroleum industry, which needs a lot of work. Companies in the Middle East region are not fully aware of significances of environmental protection policies, and thus, unintentionally risk the environment by further exploration and production activities. Given the fact that almost half of the respondents to this survey indicated that there is no specific department responsible for sustainability in their organization, a comprehensive approach must be taken to educate managers and employees to improve the quality of services to the industry and relevant customers now, and in coming future(Dima et al., 2017).

\section{References}

Banerjee, S. B. (2017). Transnational power and translocal governance: The politics of corporate responsibility. Human Relations, 0018726717726586.

BP. (2017a). Energy outlook 2017. Retrieved from http://www.bp.com/content/dam/bp/pdf/energy-economics/energy-outlook2017/bp-energy-outlook-2017.pdf

BP. (2017b). Statistical Review of World Energy. Retrieved from https://www.bp.com/content/dam/bp/en/corporate/pdf/energy-economics/ statistical-review-2017/bp-statistical-review-of-world-energy-2017-full-report.pdf

Bratianu, C., \& Bolisani, E. (2015). Knowledge strategy: an integrated approach for managing uncertainty. Paper presented at the 16th European Conference on Knowledge Management, University of Udine, Italy.

Dima, A. M., Hadad, S., \& Luchian, I. (2017, July). Review on the dimensions of businessuniversity alliances. In Proceedings of the International Conference on Business Excellence (Vol. 11, No. 1, pp. 64-73). De Gruyter Open.

Gupta, V., \& Grossmann, I. E. (2017). Offshore oilfield development planning under uncertainty and fiscal considerations. Optimization and Engineering, 18(1), 3-33.

Hall, J., \& Vredenburg, H. (2003). The challenge of innovating for sustainable development. MIT Sloan Management Review, 45(1), 61.

IEA. (2016a). "FAQ: Oil,”. Retrieved from https://www.iea.org/about/faqs/oil/

IEA. (2016b). Oil Market Report Retrieved from https://www.iea.org/about/faqs/oil/

Ite, A. E., Ibok, U. J., Ite, M. U., \& Petters, S. W. (2013). Petroleum exploration and production: past and present environmental issues in the Nigeria's Niger Delta. American Journal of Environmental Protection, 1(4), 78-90.

Miron, D., Dima, A.M. and Vasilache, S. (2010). Models of the Intra-regional Trade Influence on Economic Sustainable Development in Romania. Amfiteatru Economic, XI (27), pp. $27-35$ 
Neill, M. (2017). An Integrated Approach to Operational Risk Management-The Role of Process Safety Management. Paper presented at the SPE Health, Safety, Security, Environment, \& Social Responsibility Conference-North America.

Pérez-Lombard, L., Ortiz, J., \& Pout, C. (2008). A review on buildings energy consumption information. Energy and buildings, 40(3), 394-398.

Ramos, S. B., Taamouti, A., Veiga, H., \& Wang, C.-W. (2017). Do investors price industry risk? PICBE | 638 Evidence from the cross-section of the oil industry. Journal of Energy Markets.

Regnier, E. (2007). Oil and energy price volatility. Energy Economics, 29(3), 405-427.

Schneider, J., Ghettas, S., Merdaci, N., Brown, M., Martyniuk, J., Alshehri, W., \& Trojan, A. (2013). Towards sustainability in the oil and gas sector: benchmarking of environmental, health, and safety efforts. Journal of Environmental Sustainability, $3(3), 6$.

Schweitzer, D. (2010a). Oil Companies and Sustainability: More than Just an Image? Retrieved from www.deepblue.lib.umich.edu

Schweitzer, D. (2010b). Oil Companies and Sustainability: More than Just an Image?

Tantau, A. D., Khorshidi, M., \& Mojarad, A. A. S. (2017, July). International Oil Companies Sustainability after Oil Price decline. In Proceedings of the International Conference on Business Excellence (Vol. 11, No. 1, pp. 157-167). De Gruyter Open.

Tomlinson, K. (2017). Oil and gas companies and the management of social and environmental impacts and issues: The evolution of the industry's approach (9292562460). Retrieved from https://www.econstor.eu/

UNDP. (2016). Oil And Gas Industry To The Sustainable Development Goals: An ATLAS. Retrieved from The UN High-Level Political Forum: WWW.undp.org

Weaver, J. L. (2003). Sustainable development in the petroleum sector. Energy law and sustainable development. IUCN, Environmental Policy and Law Paper(47).

WEF. (2016). Trust Challenge Facing the Global Oil \& Gas Industry. Retrieved from www.weforum.org

Whitson, C. H. (2009). International vs. National Oil Companies-What's the Difference? The Way Ahead, 5(03), 10-11. 